\title{
DESVELANDO OS EXAMES DE ADMISSÃO AO GINÁSIO NA EDUCAÇÃO PARANAENSE ${ }^{1}$
}

\author{
Elisângela Zarpelon Aksenen ${ }^{2}$ \\ Maria Elisabeth Blanck Miguel ${ }^{3}$
}

\section{RESUMO}

O estudo aqui apresentado pretende compreender como funcionaram os exames de admissão ao ginásio na realidade educacional paranaense. Por meio do Decreto ${ }^{\circ} 19.890$ de 18 de abril de 1931, como parte da Reforma Francisco Campos, tais exames tornaramse obrigatórios nas escolas de todo o Brasil até o ano de 1971 e marcaram um período histórico de restrição no acesso ao ginásio. A análise da legislação, o estudo da situação econômica, social e política do Paraná, articulada ao contexto nacional e o papel dos exames na realidade educacional paranaense situam a abordagem aqui apresentada. Entendemos que o contato com as fontes cria a possibilidade de reconstruir o passado, que somente será compreendido quando articulado ao contexto no qual foi produzido (BLOCH, 2001). Apontamos elementos da legislação, a análise do momento histórico no qual os exames de admissão estão inseridos, as orientações para as provas de matemática e procuramos desvelar o papel de tais exames na realidade educacional brasileira e paranaense. Percebemos, ao longo do período em que os exames de admissão ao ginásio foram aplicados, algumas mudanças estruturais regulamentadas e principalmente, um dispositivo de controle e poder devido ao seu caráter extremamente seletivo.

Palavras chave: Exames de Admissão ao Ginásio; Paraná; Matemática.

\section{UNVEILING THE ADMISSION TESTS IN THE SECONDARY SCHOOL AT THE EDUCATION SYSTEM OF PARANÁ STATE}

\begin{abstract}
The present study aims to understand how worked the entrance tests to the Secondary School in Paraná State educational reality. Through the Decree No. 19890 of April 18, 1931, as part of Francisco Campos Reform, such tests have become mandatory in schools through Brazil until 1971 and marked a historical period of restriction on access to the Secondary School. The analysis of the legislation, the study of economic, social and political situation of Paraná, articulated to the national context and the role of examinations in the State's educational reality, forms the approach presented here. We believe that the contact with the sources creates the possibility of reconstructing the past that will only be understood when articulated to the context in which it was produced (BLOCH, 2001). We point out elements of the legislation, the analysis of the historical moment in which the entrance exams are included, the guidelines for math tests and seek to reveal the role of such tests in the educational reality of Brazil and of the Paraná State. We noticed, over the period in which the entrance exams to the Secondary School were applied some regulated structural changes and mainly a control device and power due to its extremely selective character.
\end{abstract}

Keywords: Examination for Admission to Elementary School; Paraná State; Mathematics. 


\section{Introdução}

O estudo aqui apresentado procura compreender os exames de admissão ao ginásio, assim como os conteúdos matemáticos que faziam parte de tais exames, a partir da legislação.

Tem como problema da pesquisa: Como se constituíram, no Paraná, os exames de admissão ao ginásio no período compreendido entre 1930 e 1971 , quais suas características, seu significado e os conteúdos matemáticos que dele fizeram parte?

Neste sentido, foram definidos alguns objetivos: verificar as principais funções dos exames de admissão ao ginásio; assim como suas características; investigar como foram constituídos os programas para as provas de matemática, analisando se os mesmos sofreram alterações durante o período de abrangência de tais exames.

O objeto de pesquisa foi estudado por meio de procedimentos da pesquisa histórico-documental. Os dados foram analisados na perspectiva teórico-crítica que considera as transformações da vida material da sociedade como suporte do sistema educacional.

Por meio do Decreto n ${ }^{\circ} 19.890 / 31$, como parte da Reforma Campos, os exames de admissão ao ginásio tornaram-se obrigatórios em todas as escolas secundárias oficiais do Brasil, sendo extintos somente com a Lei $\mathrm{n}^{\circ}$ 5692/71 e marcaram um período histórico de acesso ao ensino primário e restrição ao ensino secundário.

No entanto, as fontes pesquisadas indicam que estes exames foram introduzidos no país, como parte da política de ingresso ao Colégio Imperial Pedro II, a partir de 1870, pelo Decreto $\mathrm{n}^{\circ} 4.468$, de $1^{\circ}$ de fevereiro e no Paraná, para ingresso ao Ginásio Paranaense, atual Colégio Estadual do Paraná, desde 1892, pelo Decreto n ${ }^{\circ} 3$, de 18 de outubro.

O contato com as fontes - leis, decretos, regimentos - cria a possibilidade de analisar parte da educação no Paraná e para melhor compreendê-los faz-se necessária a sua interlocução com o contexto no qual foram produzidos. Como bem afirma Bloch, "nunca se explica plenamente um fenômeno histórico fora do estudo de seu momento" (2001, p. $60)$.

Entretanto, além dos fatores sócio-econômicos, os fatores políticos também são determinantes para esta análise. Por isso, concorda-se com Romanelli (2010) quando esta afirma que "a organização da educação em determinada sociedade é, antes de tudo, um problema de ordem política" (ROMANELLI, 2010, p. 195).

As próprias políticas educacionais estão intimamente relacionadas com a conjuntura social, política e econômica do Estado; por isto a educação vem sofrendo as consequências de uma sociedade dividida pelas relações entre capital e trabalho, portanto voltada ao modo de produção. As políticas educacionais têm reforçado o dualismo estrutural que oferece diferentes formações para as diferentes classes sociais. Romanelli (2010) afirma que a escola tem ajudado a manter privilégios de classes, sendo ela mesma um privilégio, ao utilizar-se de "mecanismos de seleção escolar e de um conteúdo cultural que não foi capaz de propiciar às diversas camadas sociais sequer uma preparação eficaz para o trabalho". Para a autora "a educação tem desempenhado papeis eminentemente conservadores" (ROMANELLI, 2010, p. 25).

Nesse sentido, Bourdieu (2012) contribui ao referir-se ao capital cultural, considerando fundamental o papel da origem familiar em relação ao sucesso na vida escolar dos indivíduos, já que cada família transmite a seus filhos um conjunto de valores que lhe é próprio.

Para o autor, a escola reproduz e legitima as desigualdades sociais, uma vez que os menos favorecidos não possuem familiaridade com a cultura imposta pela classe 
dominante, que é próxima da cultura escolar, por meio dos currículos escolares, dos métodos pedagógicos, das formas de avaliação e da própria linguagem.

Mesmo concordando com Bourdieu, é necessário citar Saviani (2003), quando afirma que, ao transmitir o saber elaborado às classes menos favorecidas da sociedade, a escola, enquanto instituição burguesa possibilita o acesso aos conhecimentos que serão necessários aos alunos mais pobres que não têm, como os provenientes das classes mais favorecidas, outras oportunidades de acesso ao saber produzido por todos os homens em seu desenvolvimento histórico.

\section{O ensino secundário e os exames de admissão ao ginásio no Paraná}

O ensino secundário no Paraná foi, por vários anos, ministrado exclusivamente no Ginásio Paranaense, atual Colégio Estadual do Paraná o qual passou por muitas reformas, extinções e recriações.

O Decreto Estadual $n^{\circ} 3$, de 18 de outubro de 1892, estabeleceu condições de ingresso ao $1^{\circ}$ ano do ensino secundário. Em consonância com os Decretos Federais $n^{\circ}$ 4.468 de $1^{\circ}$ de fevereiro de 1870 e $n^{\circ} 981$ de 8 de novembro de 1890 , o Decreto $n^{\circ} 3 / 1892$, no Artigo 10, exigia idade mínima de 12 anos, atestado de vacinação e revacinação e aprovação em exame de admissão:

[...] que versará sobre leitura, escripta, noções de grammatica nacional, noções de arithmetica, systema métrico, elementos de geographia e historia, especialmente do Brazil, noções de cousas, de sciencias phisicas e de historia natural, instrucção moral e cívica, desenho, elementos de musica, grammatica e exercicios militares, trabalhos manuaes e noções praticas de agronomia (PARANÁ, Decreto nº 3/1892, Artigo 10).

No entanto, o Artigo 96, rezava:

Enquanto não houverem no Estado escolas primarias que possam ministrar os attestados referidos no art. 10 [...] realisar-se-ão no Gymnasio [...] os exames de admissão para os candidatos á matricula do $1^{\circ}$ anno.

$\S 1^{\circ}$ Estes exames constarão de leitura, dictado, grammatica portugueza, arithmetica pratica, até regra de trez inclusive, morphologia geométrica e noções de geographia geral. (PARANÁ, Decreto nº 3/1892).

Portanto, era dispensado do exame de admissão o aluno que tivesse passado por uma escola pública primária e apresentasse certificado emitido por estabelecimento oficial do Estado (Artigo 10) conforme orientação do Decreto Federal $\mathrm{n}^{\circ} 981$ a respeito das escolas primárias.

Segundo Straube (1993), em 1895, o Ginásio Paranaense encontrava-se organizado de acordo com o Ginásio Nacional e, para igualar os currículos, o Governo Estadual, por meio do Decreto ${ }^{\circ}$ 35, de 9 de fevereiro, propunha novo regulamento à Instrução Pública, com especial atenção ao ensino secundário e ao ensino normal.

O referido Decreto, bastante semelhante ao Decreto $n^{\circ} 3 / 1892$, determinava, dentre outros aspectos, o tempo de conclusão do curso ginasial de sete anos, as matérias que constituiriam o curso, o programa para cada ano. Prescrevia orientações sobre as aulas, a 
disciplina, os professores, os exames de suficiência, finais e de madureza e também sobre os exames de admissão:

Art. 217 - Haverá no Gymnasio Paranaense, depois dos respectivos exames e dos da Escola Normal, um exame de admissão para os candidatos à matrícula do $1^{\circ}$ anno do mesmo Gymnasio.

$\S 1^{\circ}$ Este exame constará de: leitura, dictado, noções de grammatica portugueza, arithmetica prática até regra de tres, inclusive, morphologia geométrica e noções de geographia geral (PARANÁ, Decreto $\mathrm{n}^{\circ}$ $35 / 1895)$.

O Decreto $\mathrm{n}^{\circ}$ 93, de 11 de março de 1901, que estabelecia o "Regulamento da Instrucção Pública" mantinha os exames de admissão ao ginásio e indicava maiores esclarecimentos sobre eles:

Art. 143. Os paes ou encarregados dos matriculandos deverão apresentar ao Director do Gymnasio, do dia 15 ao ultimo de fevereiro de cada anno, os requerimentos instruídos com todos os documentos justificativos das condições em que se acham os candidatos á matrícula.

Art. 144. Para a matrícula no primeiro anno exigir-se-ão as seguintes condições: I - Ter o candidato, no mínimo, a edade de 12 anos, provada com a competente certidão ou documento equivalente. II - Attestado de vaccinação e revaccinação. III - Certificado de que não soffre de molestia alguma contagiosa ou infecto-contagiosa. IV - Exame prévio de admissão feito na conformidade com o art. 189 d'este Regulamento (PARANÁ, Decreto nº 93/1901).

O Artigo 187 instituía que os exames deveriam ser realizados na primeira quinzena de março perante uma comissão de três professores designados pelo diretor. E assim se constituiriam:

Art. 189. Estes exames constarão de provas escriptas e oraes. As escriptas versarão: $1^{\circ}$ sobre um ditado de 10 linhas impressas de portuguez contemporaneo; $2^{\circ}$ sobre arithmetica pratica limitada ás operações e transformações relativas aos numeros inteiros e ás fracções ordinárias e decimaes. As oraes constarão de leitura de um trecho sufficientemente longo de portuguez contemporaneo, estudo sucinto da sua interpretação no todo ou em partes; ligeiras noções de grammatica portugueza e de arguição sobre arthmetica pratica nos referidos limites, systema métrico, morphologia geométrica, noções de geographia e historia do Brazil. Nas provas escriptas os candidatos deverão exhibir regular calligraphia (PARANÁ, Decreto nº 93/1901).

Quatro anos depois, foi publicado o Regulamento do Gymnasio Paranaense, Decreto $\mathrm{n}^{\mathrm{o}} 255$, de 28 de setembro de 1905, visando a equiparação ao Ginásio Nacional para atender à necessidade de harmonizar os programas do Ginásio Paranaense com os daquela instituição.

O Artigo $1^{\circ}$ esclarecia que o Ginásio Paranaense continuava a ser o principal estabelecimento de ensino secundário do Estado. 
Os Artigos 24 a 27 e 30 a 35 referiam-se à admissão dos alunos ao ginásio e não propunham mudanças, apenas reforçavam o Decreto $n^{\circ}$ 93/1901.

Wachowicz (1984) revela que em 1911 havia 568 alunos nas escolas secundárias do Estado, dentre os quais, 127 no Ginásio Paranaense.

Ranzi e Silva (2006) descrevem a situação do ensino secundário na Capital:

Pensar o ensino secundário em Curitiba, entre os meados do século XIX e início do século XX implica em considerar principalmente, a inexpressividade das matrículas e a freqüência dos alunos, o que demonstra que o ensino regular, naqueles tempos, não passava de uma ficção, isto é, uma construção idealizada mentalmente sem correspondência com as práticas sociais (RANZI E SILVA, 2006, p. 137).

Por meio da Lei Rivadávia - Decreto Federal n ${ }^{\circ}$ 8.659, de 5 de abril de 1911, o Ginásio Nacional foi denominado Colégio Pedro II. Neste momento o Ginásio Paranaense perdeu a equiparação àquele colégio, sendo necessária a reforma da legislação que se referia ao Ginásio.

Uma tentativa de reconquistar a equiparação foi propiciada por meio de um novo Regulamento do Gymnasio Paranaense, o Decreto ${ }^{\circ}$ 542, de 29 de julho de 1915, o qual se referia aos exames de admissão, nos Artigos 40 e 41.

O Artigo 40 instituía que o prazo para a abertura das inscrições ao exame de admissão seria a primeira quinzena de fevereiro. Na segunda quinzena, aconteceriam os exames. O Artigo 41 referia-se aos quesitos necessários para o requerimento à matrícula: idade mínima de 11 anos; atestado de vacinação e atestado médico para comprovar isenção de doença; atestado de bom comportamento; consentimento dos pais ou responsáveis; comprovante do pagamento da taxa.

Em 18 de outubro de 1915 foi instituído o Decreto $\mathrm{n}^{\circ}$ 710, nomeado Código de Ensino do Estado do Paraná, o qual criava as escolas intermediárias, com cursos de um ou dois anos, para a matrícula no ginásio e na Escola Normal, respectivamente. O Artigo 188 do referido Decreto rezava:

Art. $188^{\circ}$. O curso intermediario será de dous annos, valendo para a admissão á matricula no Gymnasio a approvação em exame das materias do primeiro anno e para admissão á matricula na Escola Normal a approvação em exame das materias do segundo anno (PARANÁ, Decreto n ${ }^{\circ}$ 710/1915).

Portanto, o Decreto $\mathrm{n}^{\mathrm{o}} 710$, retirou a necessidade de exame de admissão ao ginásio, substituindo-o pela necessidade de aprovação nas matérias do $1^{\circ}$ ano do curso intermediário.

O Ginásio Paranaense voltou a ser equiparado ao Colégio Pedro II pela Portaria de 18 de agosto de 1917, por estar de acordo com os requisitos exigidos no Artigo 14 do Decreto Federal no 11.530 de 18 de março de 1915.

O Decreto Federal $\mathrm{n}^{\circ}$ 11.530, conhecido como Lei Maximiliano, reorganizou o ensino secundário e superior na República, dando autonomia didática e administrativa aos estabelecimentos de ensino secundário.

No que se referia à matrícula no Colégio Pedro II, o Decreto mantinha os exames de admissão:

Art. 97. Para requerer matriculas no Collegio Pedro II os Paes e tutores dos menores devem comprovar: a) contar o candidato mais de 11 anos de idade, e, se pretender cursar o internato, menos de 14; b) achar-se 
habilitado a emprehender o estudo das materias do curso gymnasial. Para isto o candidato se sujeitará a um exame de admissão, que constará de prova escripta em que revele o conhecimento da lingua vernácula (dictado), e prova oral, que versará sobre leitura com interpretação do texto, rudimentos de historia do Brazil, arithmetica e geometria pratica, e geographia physica (BRASIL, Decreto $\left.{ }^{\circ} 11.530 / 1915\right)$.

Consequentemente, em 28 de setembro de 1917 foi instituído o Regimento Interno do Gymnasio Paranaense - Decreto ${ }^{\circ} 675$ - que versava sobre os exames de admissão nos Artigos 12 a 14 e 29, orientando os pais a requererem o exame entre os dias 18 a 28 de fevereiro de cada ano, esclarecendo que as inscrições para o exame de admissão e as matrículas seriam anunciadas por editais, fixados na portaria do estabelecimento e publicados pela imprensa com quinze dias de antecedência e justificando que tais exames objetivavam provar que o candidato estaria preparado ao estudo das disciplinas do curso ginasial. $\mathrm{O}$ exame de admissão seria realizado na primeira quinzena de março e

[...] constará de prova escripta (dictado), em que prove o conhecimento elementar da lingua vernácula, e prova oral, que versará sobre leitura com interpretação de texto facil, rudimentos de Historia do Brazil, Arithmetica e Geometria pratica, e Geographia Physica, segundo programas observados no Collegio Pedro II (PARANÁ, Decreto nº 675/1917).

Em nível nacional, após a criação do Ministério da Educação e Saúde Pública em 1930, sob a responsabilidade de Francisco Campos foram publicados vários decretos com a finalidade de reformar o ensino superior (Decretos $n^{\circ} 19.851$ e $\mathrm{n}^{\circ} 19.852$ de 11/04/1931), o ensino secundário (Decreto $\mathrm{n}^{\circ} 19.890$ de 18/04/1931) e o ensino comercial (Decreto $\mathrm{n}^{\circ}$ 20.158, de 30/06/1931). Este conjunto de decretos ficou conhecido como Reforma Francisco Campos, a qual organizou o ensino secundário em dois ciclos: um fundamental, de cinco anos e outro complementar, de dois anos, visando à preparação para o ensino superior.

Como parte dessa reforma, o Decreto $\mathrm{n}^{\circ} 19.890$ de 18/04/1931 tornou obrigatórios os exames de admissão ao ginásio para o ingresso em todas as instituições oficiais de ensino secundário do país. Portanto, legitimou o recrutamento de alunos e impôs barreiras institucionais de acesso ao ginásio, por meio destes exames.

O referido decreto instituiu, em seu Artigo 18, os exames de admissão ao ginásio: "O candidato à matrícula na $1^{\text {a }}$ série de estabelecimento de ensino secundário prestará exame de admissão na segunda quinzena de fevereiro." O Artigo 22 descreveu o conteúdo e a forma das provas:

O exame de admissão constará de provas escritas, uma de português (redação e ditado) e outra de aritmética (cálculo elementar), e de provas orais sobre elementos dessas disciplinas e mais sobre rudimentos de Geografia, História do Brasil e Ciências naturais (BRASIL, Decreto ${ }^{\circ}$ $19.890 / 31)$.

Portanto, Francisco Campos, por meio do Decreto 19.890/1931, instituiu em nível nacional o exame de admissão ao ginásio, que foi uma prática de adesão ao ensino secundário verificada oficialmente no Colégio Pedro II a partir de 1870 e posteriormente, em outras instituições consideradas oficiais por estarem equiparadas a este colégio. 
Em 1942, o Ministro da Educação Gustavo Capanema, empreendeu novas reformas de ensino regulamentadas por diversos decretos-leis assinados de 1942 a 1946 cujo conjunto foi chamado de "Leis Orgânicas do Ensino", que organizaram cada nível de ensino.

A Lei Orgânica do Ensino Secundário (Decreto Lei no 4.244 de 9 de abril de 1942), no Capítulo VI, Artigo 34, referia-se especificamente aos exames de admissão, mantendo duas épocas para sua realização, uma em dezembro outra em fevereiro. Nos exames de segunda época poderiam inscrever-se os candidatos que não tivessem prestado ou não tivessem sido aprovados nos exames de primeira época. Prescrevia também que o candidato não aprovado num estabelecimento de ensino secundário, não poderia repeti-lo em outro, na mesma época.

A Lei $n^{\circ}$ 4.024/61, que fixou as Diretrizes e Bases da Educação Nacional, orientou os Estados a organizarem seus sistemas de ensino de acordo com seus preceitos e mantinha os exames de admissão em seu Art. 36, o qual rezava:

O ingresso na primeira série do $1^{\circ}$ ciclo dos cursos de ensino médio depende de aprovação em exame de admissão, em que fique demonstrada satisfatória educação primária, desde que o educando tenha onze anos completos ou venha a alcançar essa idade no correr do ano letivo (BRASIL, Lei $n^{\circ}$ 4.024/1961).

Portanto, a Lei Estadual $n^{\circ}$ 4.978, de 5 de dezembro de 1964, estabeleceu o sistema estadual de ensino, sendo ele organizado por: a) educação de grau primário, inclusive educação pré-primária; b) educação de grau médio (ministrada em dois ciclos, o ginasial e o colegial e abrangia o ensino secundário, técnico e profissional e o ensino normal); c) educação de grau superior.

No que diz respeito aos exames de admissão ao ginásio, a Lei Estadual n 4.978/64, foi sucinta:

Art. 102 - Aos alunos que concluírem a quinta série do ensino primário, em grupos e casas escolares, ou a quarta série em escolas isoladas, será permitida a inscrição em exame de admissão para o ingresso na primeira série, do $1^{\circ}$ ciclo dos cursos de ensino médio (PARANÁ, Lei Estadual $n^{\circ}$ 4.978/64).

No entanto, o parágrafo único do artigo 103, rezava:

Parágrafo único - Ao aluno que houver concluído a sexta série primária, inclusive com aprovação em exame final das disciplinas obrigatórias da primeira série, do $1^{\circ}$ ciclo do ensino médio, será facultado o ingresso na segunda série, do $1^{\circ}$ ciclo de qualquer curso de grau médio, independentemente de exame de admissão (PARANÁ, Lei Estadual $n^{\circ}$ 4.978/64).

Finalmente, a Deliberação no 42/71 de 09 de novembro de 1971, em consonância com a Lei Federal 5.692/71, estabeleceu normas para o acesso à primeira série do curso ginasial e, no seu artigo $1^{\circ}$, extinguiu os exames de admissão ao ginásio, conforme segue: "Art. 1" - Fica abolido para o Sistema Estadual de Ensino, compreendendo Estabelecimento Oficial e Particular, o Exame de Admissão, de acordo com o art. 87, da Lei 5.692, de 11 de agosto der 1971" (PARANÁ, Deliberação $n^{\circ}$ 42/71). 
Consequentemente, para o ingresso à $1^{\mathrm{a}}$ série do curso ginasial, bastaria a aprovação na $5^{\mathrm{a}}$ série da escola primária.

\section{Orientações inerentes à disciplina de Matemática}

As provas de matemática que faziam parte do exame de admissão ao ginásio tinham como objetivo demonstrar o nível de compreensão de conteúdos básicos de matemática para que o aluno tivesse condições de acompanhar o curso ginasial, nesse campo do conhecimento. No estudo realizado, aprofunda-se o conhecimento sobre tal questão.

O Decreto Estadual no 373, de 20 de fevereiro de 1934, criou o curso pré-ginasial, sem ônus ao Governo, a fim de preparar os candidatos ao exame de admissão.

$\mathrm{O}$ Artigo 33 referia-se às provas, assim descritas:

Art. 33 - O exame de admissão constará das seguintes disciplinas: português (ditado e redação), aritmética (cálculo elementar), rudimentos de geografia geral e corografia do Brasil, de história do Brasil e de ciências naturais.

$\S 1^{\circ}$ Haverá uma prova escrita de português e outra de aritmética. [...]

$\S 3^{\circ}$ A prova escrita de aritmética constará de três problemas elementares e práticos.

$\S 4^{\circ}$ A prova oral constará do seguinte: [...]; b) resolução de questões faceis e práticas de cálculo aritmético; [...] (PARANÁ, Regulamento Especial Curso Pre-Ginasial/1934).

Não foram encontradas leis estaduais inerentes especificamente à Matemática presente nos exames de admissão ao ginásio. Portanto, acredita-se que a legislação federal tenha orientado a elaboração e execução das provas.

A Portaria Federal $\mathrm{n}^{\circ} 142$, de 24 de abril de 1939, determinava que as provas escritas de Português e Aritmética fossem realizadas no mesmo dia e tivessem caráter eliminatório, não podendo prestar exame oral o aluno que obtivesse nota inferior a cinquenta (50) em qualquer das disciplinas. Previa também os conteúdos que deveriam ser cobrados em cada prova e os critérios de correção.

De acordo com a referida Portaria, no item 20, a prova escrita de Aritmética deveria conter no mínimo, cinco problemas elementares e práticos. $\mathrm{O}$ item 23 referia-se às provas orais que:

Constarão de arguições sobre pontos sorteados dentre os 20 (vinte) em que serão divididos os programas. Cada examinador deverá arguir o candidato no mínimo durante 5 (cinco) minutos (BRASIL, Portaria $\mathrm{n}^{\circ}$ 142/1939).

A Portaria $n^{\circ} 479$, de 30 de novembro de 1940, alterava as instruções e programas aos exames de admissão, fixando para a disciplina de Matemática, o seguinte programa:

Número. Algarismos arábicos e romanos. Numeração decimal: unidade de diversas ordens, leitura e escrita dos números inteiros. Operações fundamentais sobre números inteiros. Prova real e prova dos nove. Divisibilidade por 10, 2, 5, 9 e 3. Número primo. Decomposição de um número em fatores primos. Máximo divisor comum. Mínimo múltiplo comum. Fração ordinária. Fração própria, fração imprópria, número 
mixto. Extração de inteiros. Simplificação de frações e redução ao mesmo denominador. Comparação de frações. Números decimais. Operações sobre números decimais. Conversão das frações ordinárias em decimais e vice-versa. Exercícios fáceis sobre expressões em que entrem frações ordinárias e decimais, para a aplicação das regras de conversão e das operações. Noções de sistema métrico decimal. Metro; metro quadrado e metro cúbico; múltiplos e submúltiplos. Litro; múltiplos e submúltiplos. Grama; múltiplos e submúltiplos. Sistema monetário brasileiro. Resolução de problemas fáceis, inclusive sobre as medidas do sistema métrico decimal (BRASIL, Portaria nº 479/1940).

A Circular $n^{\circ} 13$, de 3 de dezembro de 1940, alterava as instruções e os programas para o exame de admissão e chamava a atenção para determinados conteúdos, na época, chamados de "pontos". De acordo com esta Circular, a prova escrita de Matemática procurava apurar o domínio das operações fundamentais e o desembaraço no cálculo. A orientação recomendava ainda, para que fossem evitados problemas e exercícios de fácil resolução, conhecidos hoje, como questões de raciocínio lógico.

A prova escrita de MATEMÁTICA viza de modo especial, apurar o domínio das operações fundamentais e o desembaraço no cálculo. Os problemas e exercícios propostos devem, portanto, verificar, realmente esses dois pontos, evitando-se os de exposição intricada e fácil resolução, como são geralmente os chamados "quebra-cabeças" (BRASIL, Circular $\left.n^{\circ} 13 / 1940\right)$.

Em relação aos exames orais de Matemática, que deveriam durar 5 minutos, a Circular recomendava que se empregassem cálculos mentais rápidos, expressões aritméticas simples e problemas de raciocínio simples.

Devem ser evitadas as definições teóricas, e quase sempre confusas, de morfologia geométrica. Esse ponto aliás, convém esclarecer, não consta dos programas, mas é geralmente incluído no exame de admissão por fazer parte do curso primário de alguns Estados da União. São recomendáveis: cálculos mentais rápidos, desenvolvimento de expressões aritméticas simples e problemas de raciocínio simples (BRASIL, Circular $\left.n^{\circ} 13 / 1940\right)$.

A Portaria ${ }^{\circ}$ 681-A, de 30 de novembro de 1942, do Departamento Nacional de Educação, expedia instruções para os exames de admissão à $1^{\mathrm{a}}$ série ginasial no ano letivo de 1943. Para o programa de Matemática, a única alteração foi a dispensa do ponto que tratava do "sistema monetário brasileiro".

As provas do exame de admissão para aquele ano deveriam ser escritas e orais de Português e Matemática - de caráter eliminatório, onde o candidato deveria obter, no mínimo, nota 5 - e provas orais de História e Geografia do Brasil. As instruções para as provas orais mantiveram-se inalteradas. "A prova escrita de Aritmética constará, no mínimo, de cinco problemas elementares e práticos" (BRASIL, Portaria n ${ }^{\circ}$ 681-A/ 1942).

A Portaria $\mathrm{n}^{\circ}$ 610, de 17 de novembro de 1943, revigorou, para o ano letivo de 1944, as instruções da Portaria $\mathrm{n}^{\circ}$ 681-A, citada anteriormente. No entanto, este documento reintroduziu nos exames de admissão ao ginásio, o conteúdo referente ao Sistema Monetário. 
A Circular $n^{\circ}$ 1/1951 estabeleceu também os programas para o exame de admissão. Para a Matemática o programa era composto pelos conteúdos:

Número. Algarismos arábicos e romanos. Numeração decimal: unidade das diversas ordens, leitura e escrita dos números inteiros. Operações fundamentais sôbre os números inteiros. Prova real. Divisibilidade por 10, 2, 5, 9 e 3. Prova dos nove. Número primo. Decomposição de um número em fatôres primos. Máximo divisor comum. Mínimo múltiplo comum. Fração ordinária. Fração própria, imprópria, número misto. Extração de inteiros. Simplificação de frações e redução ao mesmo denominador. Comparação de frações. Números decimais fracionários. Operações sôbre números decimais. Conversão das frações ordinárias em números decimais e vice-versa. Exercícios fáceis sôbre expressões em que entrem frações e números decimais, para a aplicação das regras de conversão e das operações. Noções sôbre o sistema legal de unidades de medir. Metro, metro quadrado e metro cúbico; múltiplos e submúltiplos usuais. Litro; múltiplos e submúltiplos usuais. Quilograma: múltiplos e submúltiplos usuais. Sistema monetário brasileiro. Resolução de problemas fáceis, inclusive sôbre o sistema legal de unidades de medir (BRASIL, Circular n ${ }^{\circ}$ 1/1951).

As orientações para as provas de Matemática não diferiam, em essência, daquelas dadas pela Portaria $n^{\circ} 193 / 1950$, exceto quanto ao tempo de duração das provas, que passou de 60 para 90 minutos. As provas orais deveriam durar no mínimo 5 minutos e no máximo, 10 minutos.

A Portaria $\mathrm{n}^{\circ}$ 501, de 19 de maio de 1952, que expedia instruções relativas ao Ensino Secundário referia-se aos exames de admissão a partir do artigo $1^{\circ}$ no qual mantinha as duas épocas do exame, sendo oferecida segunda chamada ao candidato impedido de participar da primeira devido a doença, solenidade ou motivo de luto decorrente de falecimento de parente próximo. A Portaria mantinha as demais orientações para a inscrição e realização dos exames de admissão.

As orientações para a prova escrita de Matemática sofreram leves alterações descritas no parágrafo $2^{\circ}$ do artigo $3^{\circ}$ :

A prova escrita de matemática constará de: a) Cinco questões simples, sob forma de problema, às quais, no julgamento em conjunto, deverão ser atribuídos até 5 pontos; b) Cinco questões, de caráter prático imediato, compreendendo o programa da disciplina, às quais, no julgamento, deverão ser dados, no conjunto até 5 pontos (BRASIL, Portaria $\mathrm{n}^{\circ}$ 501/1952).

O parágrafo $6^{\circ}$ referia-se às provas orais:

As provas orais constarão de argüições sôbre pontos sorteados dentre 20 (vinte) formulados sôbre a matéria dos programas respectivos. [...] Cada examinador deverá argüir o candidato durante cinco minutos no mínimo, e quinze no máximo (BRASIL, Portaria nº 501/1952).

O Artigo 13 citou os programas de cada disciplina que compunham o exame de admissão. Com pequenas alterações em relação à Circular $n^{\circ} 1 / 1951$, estabeleceu para a matemática o seguinte programa: 
Números inteiros. Algarismos arábicos e romanos. Numeração decimal. Operações fundamentais sôbre números inteiros. Divisibilidade por 10, 2, 5, 9 e 3. Prova real e dos nove. Números primos. Decomposição de um número em fatôres primos. Máximo divisor comum e mínimo múltiplo comum de dois ou mais números. Frações ordinárias: simplificação e comparação. Operações sôbre frações ordinárias e números mistos. Números decimais fracionários; operações. Conversão das frações ordinárias em números decimais e vice-versa; números decimais periódicos. Noções sôbre o sistema legal de unidades de medir. Metro, metro quadrado e metro cúbico; múltiplos e submúltiplos usuais. Litro; múltiplos e submúltiplos usuais. Quilograma; múltiplos e submúltiplos usuais. Sistema monetário brasileiro. Problemas simples, inclusive sôbre o sistema legal de unidades de medir (BRASIL, Portaria $\mathrm{n}^{\circ}$ 501/1952).

A Portaria $\mathrm{n}^{\mathrm{o}} 325$, de 13 de outubro de 1959, expedia novas instruções para os exames de admissão ao ginásio. Sobre os programas de Matemática, rezava o Artigo $12^{\circ}$ :

[...] II - O programa de matemática poderá abranger, no máximo, o cálculo elementar aritmético, a morfologia geométrica essencial às aplicações desse cálculo e as unidades de uso mais corrente do sistema métrico brasileiro (BRASIL, Portaria nº 325/1959).

A Circular $\mathrm{n}^{\mathrm{o}} 3$, de 11 de novembro de 1959, expedia instruções e esclarecimentos para a execução da Portaria $\mathrm{n}^{\circ} 325$, de 13 de outubro de 1959. Portanto, a Circular reforçava as orientações apresentadas na Portaria e, no que se refere à prova de Matemática, determinava que a existência da prova oral ficasse a critério do estabelecimento.

\section{Considerações finais}

Os exames de admissão ao ginásio inseriram-se em um período no qual a sociedade paranaense, assim como a sociedade brasileira, passava por diversas modificações sociais, políticas e econômicas. Em decorrência destas modificações a procura por mão de obra qualificada aumentou, o que provocou um consequente aumento na demanda pela educação.

Ao longo do vasto período em que existiram, os exames de admissão ao ginásio sofreram muitas alterações, legitimadas por decretos, portarias, circulares, pareceres que foram cuidadosamente analisados durante a elaboração desta pesquisa.

À luz da legislação vigente, os exames de admissão ao ginásio podem ser considerados mecanismos de seleção, controle e restrição do acesso à continuidade nos estudos. Inseridos em um período da educação brasileira no qual o ensino secundário foi marcado pelo caráter elitista e enciclopédico, rigidamente controlado por um sistema de provas.

Compreende-se que o ingresso ao ginásio por meio dos exames de admissão tenha marcado a educação brasileira por um mecanismo de valorização de uns em detrimento a outros, desconsiderando as possibilidades de cada indivíduo, suas origens, seus estímulos e as próprias diferenças individuais.

O estudo da Matemática presente nos exames de admissão ao ginásio revela a necessidade de domínio de conteúdos mínimos para o acesso ao ginásio. Entretanto, os conteúdos exigidos pela legislação sofreram poucas alterações durante o período. 
Cabe-nos refletir se os exames de admissão ao ginásio tiveram somente a função de bloquear o acesso de grande parte da população ao ginásio ou se realmente foram uma forma de verificar conhecimentos necessários à continuidade dos estudos.

\section{REFERÊNCIAS}

BLOCH, Marc. Apologia da História ou o Ofício de Historiador. Rio de Janeiro: Jorge Zahar Ed., 2001.

BOURDIEU, Pierre. Escritos de Educação. NOGUEIRA, Maria Alice; CATANI, Afrânio (org.). 13 ed. Petrópolis, RJ: Vozes, 2012.

BRASIL. Decreto $\mathbf{n}^{\mathbf{0}} \mathbf{4 . 4 6 8}$, de $1^{\circ}$ de fevereiro de 1870 . Altera os regulamentos relativos ao Imperial Collegio de Pedro II. Disponível em: <http://www2.camara.gov.br/legin/fed/decret/1824-1899/decreto-4468-1-fevereiro-1870552830-publicacaooriginal-70377-pe.html > Acesso em 13/09/2012.

Decreto no 981, de 8 de novembro de 1890. Approva o Regulamento da Instrucção Primaria e Secundaria do Districto Federal. Disponível em: $<$ http://www2.camara.gov.br/legin/fed/decret/1824-1899/decreto-981-8-novembro-1890515376-publicacaooriginal-1-pe.html > Acesso 13/09/2012.

Decreto $\mathbf{n}^{\mathbf{0}}$ 8.659, de 5 de abril de 1911. Approva a lei Organica do Ensino Superior e do Fundamental na Republica. Disponível em: <http://www2.camara.gov.br/legin/fed/decret/1910-1919/decreto-8659-5-abril-1911517247-publicacaooriginal-1-pe.html> Acesso em 25/09/2012.

Decreto no $\mathbf{1 1 . 5 3 0}$, de 18 de março de 1915. Reorganiza o ensino secundario e o superior na Republica. Disponível em: <http://www2.camara.gov.br/legin/fed/decret/19101919/decreto-11530-18-marco-1915-522019-republicacao-97760-pe.html> Acesso em 21/09/2012.

\section{Ensino Secundário. Disponível em: <http://www.histedbr.fae.unicamp.br/navegando/fontes_escritas/5_Gov_Vargas/decreto $\% 2$ 019.890-\%201931\%20reforma\%20francisco\%20campos.htm > Acesso em 09/08/2011.}

Portaria $\mathrm{n}^{\circ}$ 142, de 24 de abril de 1939. In: BICUDO, J. de Campos. O ensino secundário no Brasil e sua atual legislação (1931 a 1941). São Paulo, 1941, p. 311-315.

Portaria $\mathrm{n}^{\mathrm{o}}$ 479, de 30 de novembro de 1940. In: BICUDO, J. de Campos. O ensino secundário no Brasil e sua atual legislação (1931 a 1941). São Paulo, 1941, p. 433-436.

Circular $\mathrm{n}^{\text {o } 13, \text { de }} 03$ de dezembro de 1940. In: BICUDO, J. de Campos. O ensino secundário no Brasil e sua atual legislação (1931 a 1941). São Paulo, 1941, p. $542-544$. 
Decreto-Lei no 4.244, de 09 de abril de 1942. Aprova a Lei Orgânica do Ensino Secundário. Disponível em: 〈http://www.soleis.adv.br/leiorganicaensinosecundario.htm > Acesso em 13/05/2011.

Portaria $n^{\circ}$ 681-A, de 30 de novembro de 1942. In: BICUDO, J. de Campos. O ensino secundário no Brasil e sua atual legislação (de setembro de 1942 a julho de 1943). Suplemento ${ }^{\circ}$ 2. São Paulo, 1943, p. 33-36.

PORTARIA $\mathrm{n}^{\circ}$ 501, de 19 de maio de 1952 e legislação complementar (atualizado até março de 1960). Suplemento da Revista Atualidades Pedagógicas. Editora Companhia Editora Nacional. 183 páginas. Documento encontrado no Centro de Memória do Colégio Estadual do Paraná.

. Lei $\mathbf{n}^{\mathbf{0}}$ 4.024, de 20 de dezembro de 1961. Fixa as Diretrizes e Bases da Educação Nacional. Disponível em: <http://www.histedbr.fae.unicamp.br/navegando/fontes_escritas/6_Nacional_Desenvolvim ento/ldb\%20lei\%20no\%204.024,\%20de\%2020\%20de\%20dezembro\%20de\%201961.htm

> Acesso em: 13/05/2011.

COLETÂNEA DA LEGISLAÇÃO ESTADUAL DE ENSINO: 1964-1967. Fundepar: Governo do Estado do Paraná. Administração Paulo Pimentel. $1^{\circ}$ Vol.

COLETÂNEA DA LEGISLAÇÃO ESTADUAL DE ENSINO: 1968. Fundepar: Governo do Estado do Paraná. Administração Paulo Pimentel. $2^{\circ}$ Vol.

MIGUEL, Maria E. Blanck. Escola Normal no Paraná: instituição formadora de professores e educadora do povo. In: José Carlos Souza Araujo; Anamaria Gonçalves Bueno de Freitas; Antônio de Pádua Carvalho Lopes. (Org.). As Escolas Normais do Império à República. Campinas: Alínea Editora, 2008, p. 145-162.

PARANÁ. Decreto n ${ }^{\circ}$ 3, de 18 de outubro de 1892. Manda observar o Regulamento para o Gymnasio Paranaense. Constituição Política, Leis e Regulamentos do Estado do Paraná. Curitiba: Typ. da Penitenciaria - AHU, 1909. Documento encontrado no Departamento Estadual de Arquivo Público do Paraná.

Decreto no 35, de 09 de fevereiro de 1895. Dá regulamento para a Instrucção Pública do Estado. Documento encontrado no Departamento Estadual de Arquivo Público do Paraná.

Decreto $\mathbf{n}^{0}$ 93, de 11 de março de 1901. Dá regulamento para a Instrucção Pública do Estado. Documento encontrado no Centro de Memória do Colégio Estadual do Paraná.

Decreto $\mathbf{n}^{\mathbf{0}}$ 255, de 28 de setembro de 1905. Regulamento do Gymnasio Paranaense. Documento encontrado no Centro de Memória do Colégio Estadual do Paraná.

Decreto $\mathbf{n}^{\mathbf{0}}$ 542, de 29 de julho de 1915. Regulamento do Gymnasio Paranaense. Documento encontrado no Centro de Memória do Colégio Estadual do Paraná. 
Decreto $\mathbf{n}^{\circ} \mathbf{7 1 0}$, de 18 de outubro de 1915. Código do Ensino do Estado do

Paraná. Disponível

em: <http://www.arquivopublico.pr.gov.br/arquivos/File/RelatoriosSecretarios/Ano_1915_MF N_1914.pdf> Acesso em 20/08/2012.

Decreto no 675, de 28 de setembro de 1917. Regimento Interno do Gymnasio Paranaense. Documento encontrado no Centro de Memória do Colégio Estadual do Paraná.

Decreto no 373, de 20 de fevereiro de 1934. Criou o curso pré-ginasial. Documento encontrado no Departamento Estadual de Arquivo Público do Paraná.

RANZI, S. M. F.; SILVA, M. C. da. Questões de legitimidade na primeira República: o ensino secundário regular a equiparação do Ginásio Paranaense ao congênere federal. Revista do Centro de Educação UFSM. Santa Maria: v. 31, n. 1, p. 133-152, jan/jun 2006.

ROMANELLI, O. de O. História da Educação no Brasil (1930/1973). 35 ed. Petrópolis: Vozes, 2010.

SAVIANI, Dermeval. Pedagogia Histórico-crítica: primeiras aproximações. Campinas, S P: Autores Associados, 2003.

STRAUBE, Ernani C. Do Licêo de Coritiba ao Colégio Estadual do Paraná: 1846 1993. Curitiba: Fundepar, 1993.

WACHOWICZ, Lílian Anna. Relação professor $\mathbf{x}$ estado no Paraná tradicional. Curitiba: Cortez, 1984.

\footnotetext{
1 Artigo apresentado no VII Congresso Brasileiro de História da Educação, realizado na Universidade Federal do Mato Grosso - Cuiabá, entre os dias 20 e 23 de maio de 2013.

${ }^{2}$ Doutoranda em Educação pela Pontifícia Universidade Católica do Paraná.

${ }^{3}$ Doutora em História e Filosofia da Educação pela Pontifícia Universidade Católica de São Paulo e docente titular da Pontifícia Universidade Católica do Paraná. Membro do HISTEDBR e da SBHE.
} 